\title{
Getting to L1 the Hard Way: Triana's Launch Options
}

\author{
Martin B. Houghton \\ NASA's G iddard Space Flight Center, Greenbelt, Maryland 20771, USA \\ houghton@ gsfc.nasa.gov・Voice: (301) 286-0694・ Fax: (301) 286-1719
}

A bstract. Over the past four years, NASA's Goddard Space Flight Center has built and tested the Triana observatory, which will be the first Earth observing science satellite to take advantage of the unique perspective offered by a Lissajous orbit about the first Earth-Sun Lagrange Point (L1). Triana was originally meant to fly on the U.S. Space Transportation System (a.k.a. the Space Shuttle), but complications with the shuttle manifest have forced Triana into a "wait and see" attitude. The observatory is currently being stored at NASA's Goddard Space Flight Center, where it waits for an appropriate launch opportunity to materialize. To that end, several possible alternatives have been considered, including variations on the nominal shuttle deployment scenario, a high inclination Delta-type launch from Vandenberg Air Force Base, a Tsyklon class vehicle launched from Baikonur, Kazakhstan, and a ride on a French Ariane vehicle out of French Guiana into a somewhat arbitrary geostationary transfer orbit (GTO). This paper chronicles and outlines the pros and cons of how each of these opportunities could be used to send Triana on its way to Ll

\section{Introduction}

The Triana observatory, built by NASA's Goddard Space Flight Center and shown in Figure 1, will be the first Earth science mission to take advantage of the unique perspective offered by a Lissajous urbit about the first Earth-Sun Lagrange Point (L1). Fron this vantage point, Triana will, for the first time ever, stnd back images of a nearly fully lit Earth disk (see Figure 2), in 10 different wavelengths (UV, visible, and near IR), 24 hours a day.

In addition to its Earth viewing instruments, Triana has a suite of solar wind (i.e. space veather) instruments. Collectively, the data from Triana will be used to drive investigations in various research areas and to set the foundation for various education and outre ach programs [1].

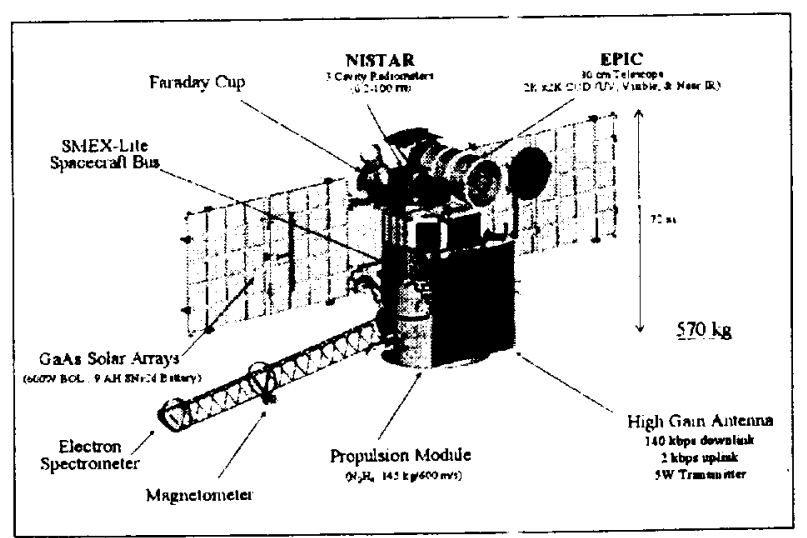

Figure 1: "Artist's rendering" of fully depl oyed Triana observatory

\section{Baseline Trajectory \& Orbit}

Triana was originally meant to $f y$ on the U.S. Space Shuttle. Its baseline trajectory is a direct transfer to a $15 \times 4$ deg (sun-earth-observatory angle) Lissajous orbit about L1. This trajectory flows diectly from a circular low Earth orbit (nominally a Space Sihuttle orbit) and has an outgoing asymptote that is essertially right along the Earth-sun line (Figure 3). It was chosen to simplify the

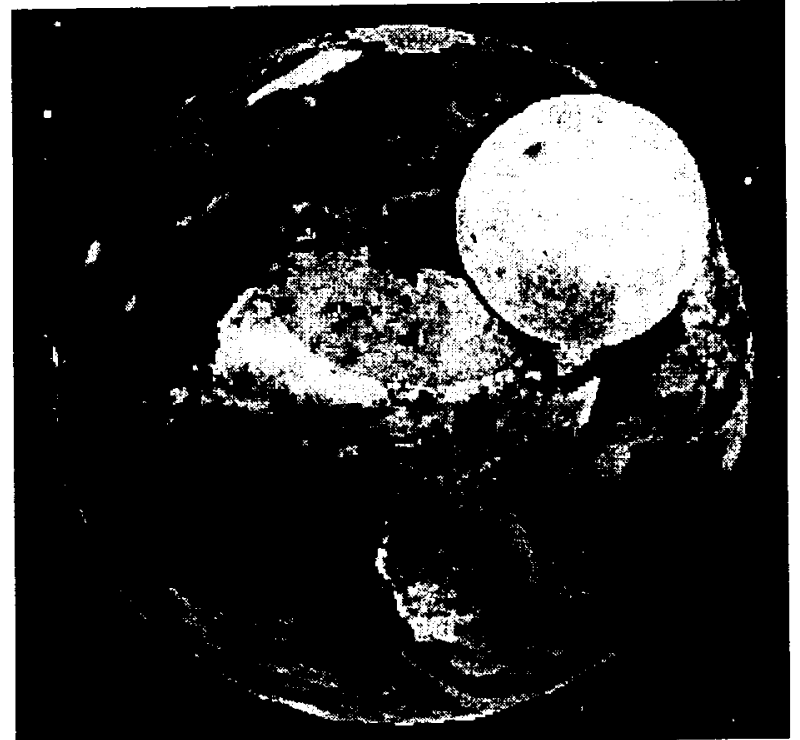

Figure 2: Image representative of those to be taken by Triana at $\mathbf{L} 1$

mission design and to minimize manifesting constraints (i.e. no lunar timing issues) with the Space Shuttle.

Triana's baseline mission orbit at L1 (a Lissajous) was designed so that the sun-earth-observatory angle never exceeds $15^{\circ}$, or goes below $4^{\circ}$. This was done to maximize the value of the science data and to avoid any communications issues, respectively. It was designed to accommodate a 2 year minimum mission with a 5 year goal (Figure 4).

\section{Triana as a Shuttle Payload}

Triana was originally meant to be flown on the U.S. Space Shuttle. As such, NASA's Goddard Space Flight Center built and tested the Gyroscopic Upper Stage (GUS) to deliver the final thrust needed to get Triana from the Shuttle's low earth orbit (LEO) to an L1 transfer trajectory and to interface Triana with the Italian Research Interim Stage (IRIS) airborne support equipment [2]. The arrangement is illustrated in Figures 5 \& 6 . 


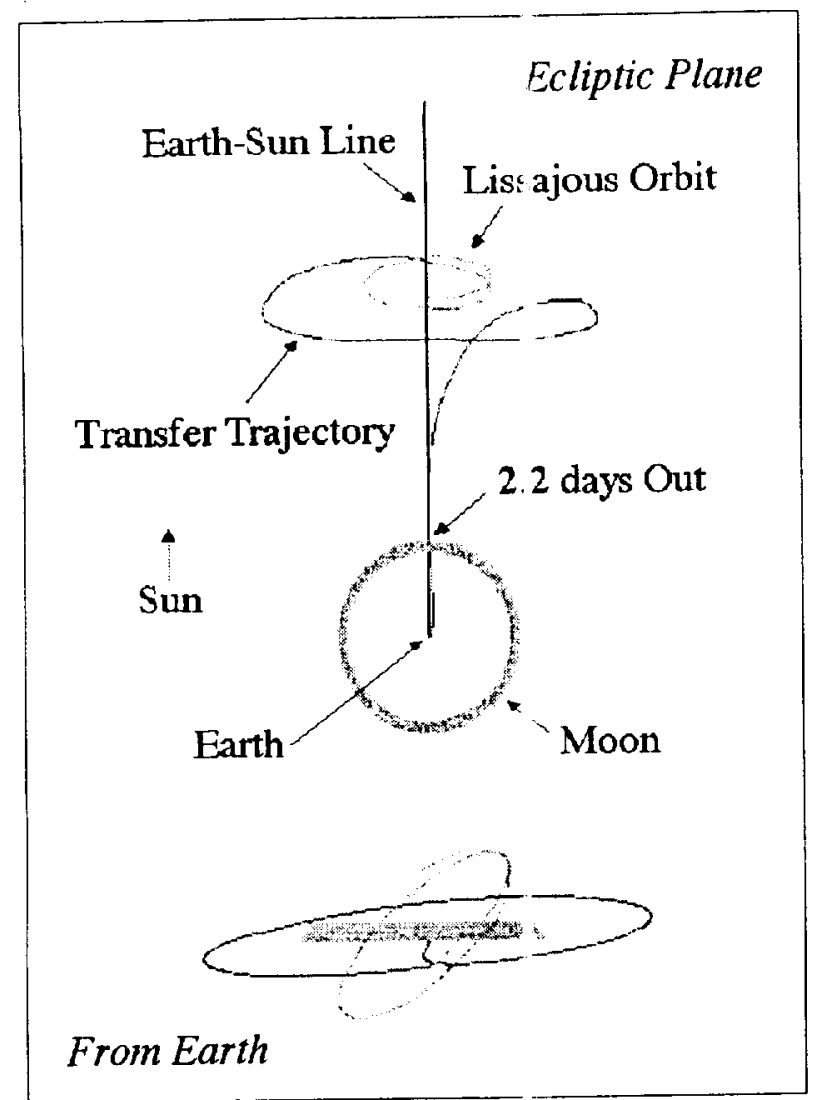

Figure 3: Views of Triana's baseline direct trajectory to L1 orbit

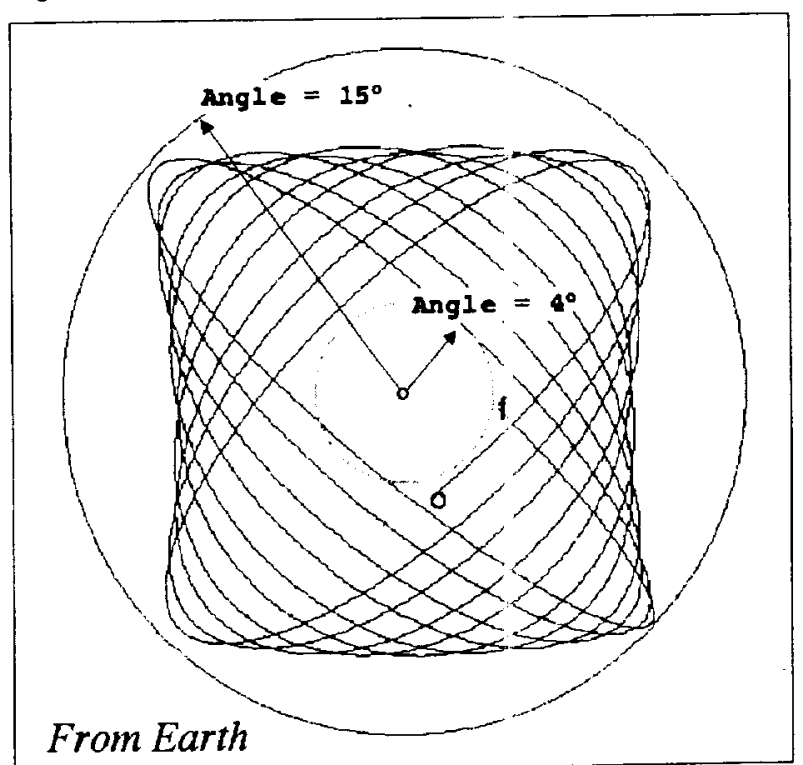

Figure 4: Triana's baseline $15 \times 4 \mathrm{deg}$ mis ion orbit (2-5 year life)

The procedure for actually flying Triana on the Space Shuttle is long and arduous, but begins with the Shuttle Program Office specifying an inclination and altitude for a given manifested mission and the (suidance, Navigation, and Control Center (GNCC) at Goildard generating firstcut LEO state vectors that match the specified conditions and are appropriate for use in getting: to L1. Goddard uses a software tool called Generator, wl ich was developed by

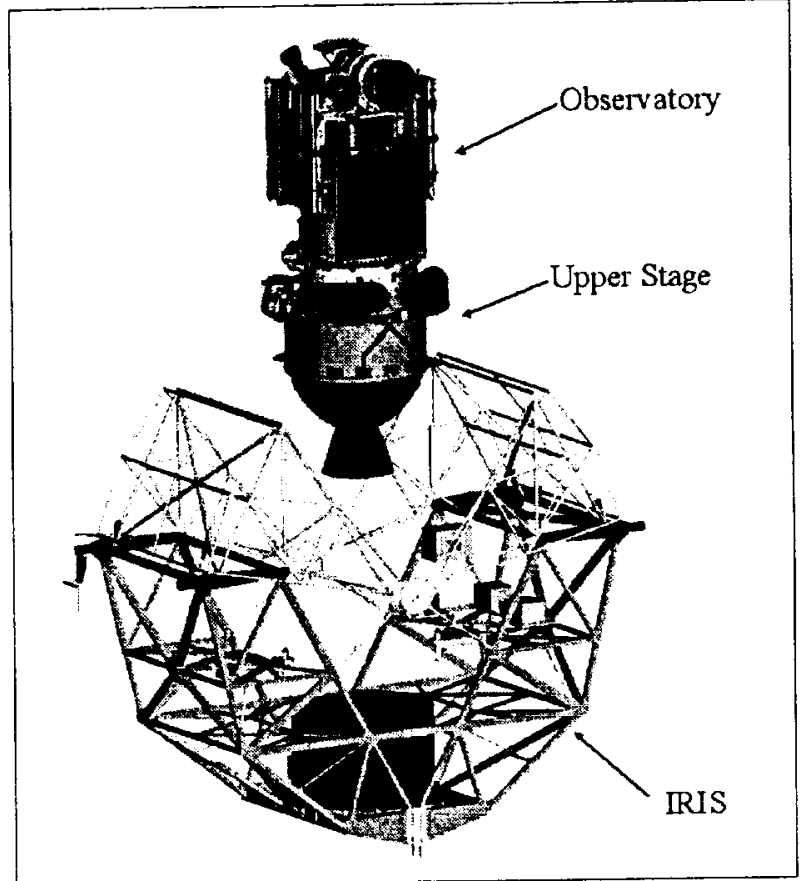

Figure 5: Triana atop its upper stage in proximity to its IRIS "cradle"

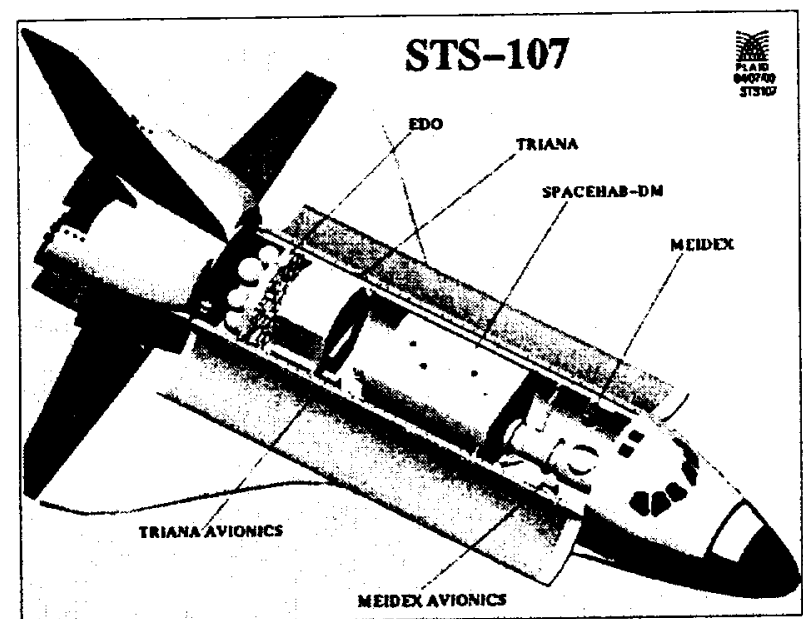

Figure 6: Triana's originally manifested STS- 107 accommodations

Purdue University in West Lafayette, Indiana. Generator uses Dynamical Systems Theory (DST) to work "backwards" (using an ephemeris model) from a given Lissajous orbit to a specific LEO state. It uses invariant manifolds (Figure 7) to get initial trajectories which it then passes through a differential corrector to match the LEO conditions. The final solutions are verified by way of "proven" software at Goddard, such as the PC-based Swingby program (which uses high-fidelity force models), and sets of Transfer Trajectory Insertion (TTI) points (and associated $\Delta V$ 's) are then produced for use by the Shuttle Program in planning the given Shuttle mission (Table 1) [3].

The Shuttle Program Office works with a given set of TTI points to determine a mission timeline in which they are able to deliver Triana to a specified TTI point at the specified time to within a specified tolerance. In terms of cross-track and along-track errors, the agreed upon toler- 


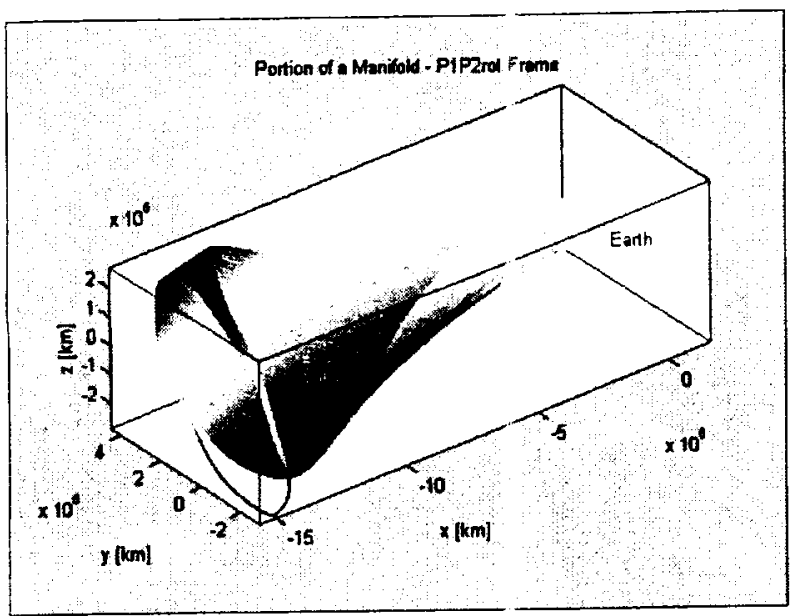

Figure 7: Sample manifold used in Triana': trajectory design process

ances boil down to $3.8^{\circ}$ in right ascension and 1 minute in release (along-track) timing. Typical Shuttle orbits regress at rates as high as $0.47^{\circ}$ per orbit, si the right ascension constraint gives the Shuttle Program a 16 orbit window to work with -8 on either side of the T II point (Figure 8).

Once Triana is released from the Shuttle and the Shutthe is given enough time to maneuver to a "safe distance", the GUS is ignited. The GUS providss a fixed $\Delta V$ that is set, by way of ballast weights, prior to launch, in order to match the required $\Delta \mathrm{V}$, as computed from the TTI table for the given mission scenario (altirude and inclination). Figure 9 shows how little the actual value changes with TTI date. The GUS is set to match the average value for a given launch period. Triana's hydrazine system is later used to make-up for any release and (jUS $\Delta V$ errors.

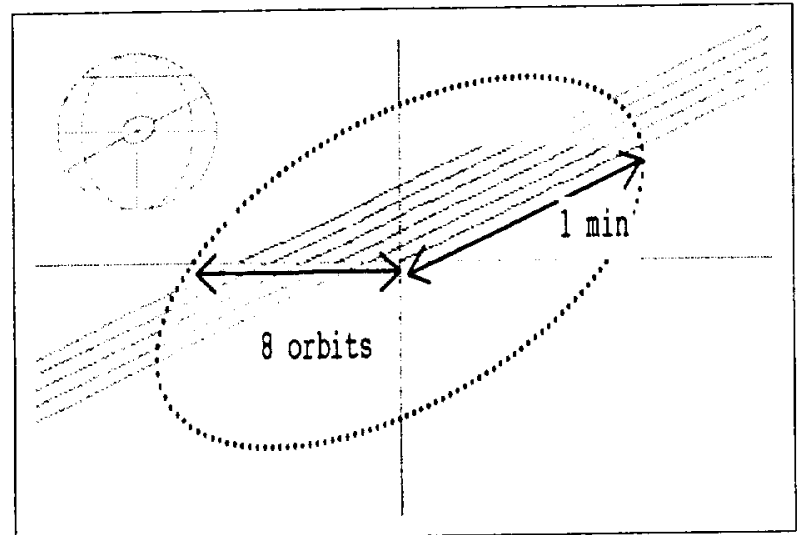

Figure 8: Triana's release window from Shuttle mission perspective

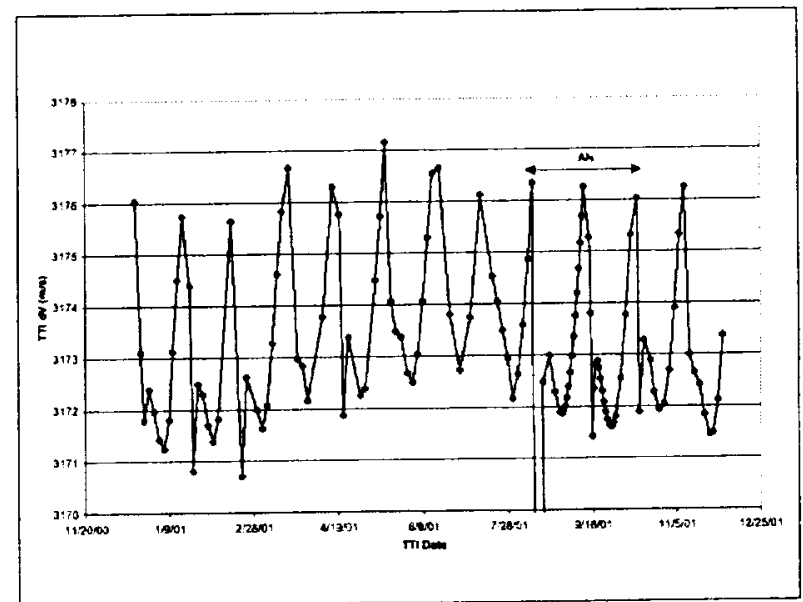

Figure 9: Representative TTI $\Delta \mathrm{V}$ variation over the course of 1 year

\begin{abstract}
TTI Date $5 \mathrm{~T}$ ime (UTC)
$03 / 12 / 2002 \quad 04: 54: 55.246$ $03 / 13 / 2002 \quad 07: 29: 08.686$

$03 / 14 / 200211: 58: 51.406$ $03 / 15 / 200213: 43: 58.606$ $03 / 16 / 200214: 19: 15.406$ $03 / 17 / 200214: 43: 35.566$

$03 / 18 / 200214: 38: 07.246$ $03 / 19 / 200214: 29: 37.486$ $03 / 20 / 200214: 20: 15.886$ $03 / 21 / 200214: 11: 54.766$ $03 / 22 / 200214: 07: 35.566$ $03 / 23 / 200214.00 \cdot 23.566$ $03 / 24 / 2002 \quad 13: 53: 02.92$
\end{abstract}

TII Date \& Time (UTO

$03 / 22 / 200040454: 55246$ $03 / 13 / 2002 \quad 07: 29: 08.686$ $03 / 14 / 2002$ 11:58:51.406 $03 / 15 / 2002 \quad 13: 43: 56.606$ $03 / 16 / 2002 \quad 14: 19: 15.406$ $03 / 17 / 2002 \quad 14: 43: 35.566$ $03 / 18 / 2002 \quad 14: 38: 07.246$ $03 / 19 / 2002 \quad 14: 29: 37.486$ $03 / 20 / 2002 \quad 14: 20: 25.8 \mathrm{B6}$ $03 / 21 / 2002$ 14:11:54.766

$03 / 22 / 2002 \quad 14: 07: 35.566$ $03 / 23 / 2002 \quad 14: 00: 23.566$ 03/24/2001 13:53:02.926

\begin{tabular}{|c|c|c|}
\hline \multicolumn{3}{|c|}{ Pre-TTI Positan ve tar (ECI MJת000) (and) } \\
\hline $\mathrm{X}-\mathrm{P} \propto \mathbf{s}$ (pre) & $\mathrm{Y}-\mathrm{p} x ;$ (pre) $\mathrm{z}-1$ & \\
\hline & & \\
\hline-6496.295660 & $-103 \ldots 834389$ & 1017.328778 \\
\hline-6533.324861 & $-111 \cdot .128821$ & 607.607440 \\
\hline-6509.307254 & -1311.011839 & 454.330635 \\
\hline-6483.153613 & $-145 \times .700794$ & 373.483822 \\
\hline $\begin{array}{l}-6457.246812 \\
-6431.384405\end{array}$ & $\begin{array}{l}-158\} .433335 \\
-160 \% .035083\end{array}$ & $\begin{array}{l}313.368529 \\
262.749165\end{array}$ \\
\hline-6405.365815 & $-179 ; .941048$ & 217.673800 \\
\hline-6379.117024 & $-18 c: .370362$ & 176.299456 \\
\hline .6352 .544855 & $-196 \div .857707$ & 137.518166 \\
\hline-6325.505068 & -2063.667391 & 100.48925 \\
\hline-6297.772497 & $-21 E 2.998693$ & 64.463595 \\
\hline-6268.927544 & $-22 \div 15.342517$ & 8.582285 \\
\hline-6238.485220 & $-23: 3.072543$ & -7.931316 \\
\hline Pre-TTI : & ve tor IALBARV & RU M. 0000 ? \\
\hline RA (deg) & $I \cdot c$ deg: & B (deg) \\
\hline -...- & $\cdots$ & \\
\hline 189.02514096 & 8. 79185282 & .0000 \\
\hline 189. 70312839 & 5. $23 \pi 1139$ & 90.0000 \\
\hline 191.40427361 & 3. 91402220 & 90.0000 \\
\hline 192. 68872125 & 3. 21672100 & 90.000 \\
\hline 193. 77808485 & 2. 69854325 & 90.0000 \\
\hline 194. 75660548 & 2. 26239085 & 90.0000 \\
\hline 195. 66247199 & 1.87411844 & 90.0000 \\
\hline 196. $514 \pi 783$ & 1. 51780227 & \\
\hline 77. 32680159 & 1. 18387106 & 90.0000 \\
\hline 198.20960415 & 0.86507153 & 90.0000 \\
\hline 198.873849 & 492557 & 90.0000 \\
\hline & 0.2460 & \\
\hline 200.4000 & .0 .06827454 & 90.0000 \\
\hline
\end{tabular}

Pre-TTI velocity vector $(0 \mathrm{~km} / \mathrm{s})$

$x$-Vel (pre) Y-Vel (pre) z-Vel (pre)

$-6.882538272-3.498582205$

$\begin{array}{lll}0.545300198 & -6.882538272 & -3.498582205 \\ 0.823688739 & -6.788818011 & -3.624969011\end{array}$

$\begin{array}{lll}0.102960140 & -6.732747449 & -3.655202927\end{array}$

$\begin{array}{llll}1.295358237 & -6.691632520 & -3.657561448\end{array}$

$\begin{array}{llll}1.453538958 & -6.654868669 & -3.675165133\end{array}$

\begin{tabular}{lll}
1.4593303689 & -6.619817798 & -3.680525835 \\
\hline
\end{tabular}

$\begin{array}{lll}3.721233509 & -6.585488814 & -3.684501314\end{array}$

$\begin{array}{llll}1.840557349 & -6.551457919 & -3.687490786\end{array}$

$\begin{array}{llll}1.953424733 & -6.517431534 & -3.689721093\end{array}$

$\begin{array}{llll}2.061569344 & -6.483115177 & -3.691335137\end{array}$

$\begin{array}{llll}2.166611243 & -6.448146761 & -3.692422921\end{array}$

$\begin{array}{lll}2.270522812 & -6.411941921 & -3.693033680\end{array}$

$\begin{array}{lll}2.375112945 & -6.373859016 & -3.693171205\end{array}$

\begin{tabular}{|c|c|c|c|c|c|}
\hline \multirow[b]{2}{*}{ (deg) } & \multirow[b]{2}{*}{ R } & \multirow[b]{2}{*}{$\mathrm{v}(\mathrm{km} / \mathrm{s})$} & \multicolumn{3}{|c|}{ TTI Thrust Unit vector (EII M, D } \\
\hline & & & $x$ funit & $Y$ (unit) & 2 \\
\hline 17.2 & 6655.937 & $\begin{array}{l}7.739945918 \\
\end{array}$ & 0.070452714 & -0.889223044 & -0.45201638 \\
\hline 118.05433633 & 6655.937 & 7.73995069 & 0.106420344 & -0.87113296 & -0.468344933 \\
\hline 18.25230998 & 6655.937 & 7.739955985 & 0.142502122 & -0.869868965 & -0.472251129 \\
\hline $\begin{array}{l}18.33302626 \\
18.38262822\end{array}$ & 6655.937 & $\begin{array}{r}7.739955150 \\
7.739954216\end{array}$ & $\begin{array}{l}0.167359915 \\
0.187796842\end{array}$ & -0.864557015 & -0.473847894 \\
\hline $\begin{array}{l}118.38252822 \\
118.4175769\end{array}$ & $\begin{array}{l}6655.937 \\
6655.937\end{array}$ & $\begin{array}{l}7.739954216 \\
7.739953149\end{array}$ & $\begin{array}{l}6842 \\
4436\end{array}$ & $\begin{array}{l}-0.859807240 \\
-0.85527\end{array}$ & $\begin{array}{l}-0.474830345 \\
-0.475523012\end{array}$ \\
\hline $\begin{array}{l}8.4175769 \\
8.4434775\end{array}$ & 6655.937 & $\begin{array}{l}53149 \\
52045\end{array}$ & $\begin{array}{l}54436 \\
82968\end{array}$ & $\begin{array}{l}-0.855272794 \\
-0.850843620\end{array}$ & $\begin{array}{l}-0.475023012 \\
-0.476036711\end{array}$ \\
\hline $\begin{array}{l}18.4434775 \\
18.46294053\end{array}$ & $\begin{array}{l}6655.937 \\
6655.937\end{array}$ & $\begin{array}{l}952045 \\
950938\end{array}$ & $\begin{array}{l}2968 \\
9614\end{array}$ & $\begin{array}{l}-0.850843620 \\
-0.846446957\end{array}$ & -0.476423018 \\
\hline $\begin{array}{l}18.46 \\
18.47\end{array}$ & $\begin{array}{l}6655.937 \\
6655.937\end{array}$ & 7.739949854 & 0.25 & -0.842050873 & -0.476711240 \\
\hline 71 & 6655.937 & 7.739948685 & 0.266354394 & -0.83767333 & 19846 \\
\hline & 555.937 & 7.739 & 0.2 & 99543 & $-0.47 \times 60458$ \\
\hline 118.4 & 6655.937 & .739946434 & 0.2 & 422002 & -0 \\
\hline $.499925 \mathrm{CB}$ & 6655.937 & .739945337 & 0.306864305 & -0.823501813 & -0.47757272 \\
\hline
\end{tabular}

Post-TT I velocity vector (ECT MI2000) $\mathrm{X}$-vel (post) Y-Vel (post) Z-Vei (post)

$0.768524656 \quad-9.699979797 \quad-4.930754184$

$\begin{array}{lll}0.161076325 & -9.569556432 & -5.10976909\end{array}$

$\begin{array}{llll}1.554967693 & -9.491915786 & -5.153153097\end{array}$

$\begin{array}{llll}2.049361716 & -9.382777809 & -5.181658659\end{array}$

$\begin{array}{llll}2.245415876 & -9.333351763 & -5.189212655\end{array}$

$\begin{array}{llll}2.426759620 & -9.284851969 & -5.194762340\end{array}$

$\begin{array}{llll}2.594951562 & -9.236721675 & -5.198892597\end{array}$

$2.754027949-9.188574452-5.201938340$

$\begin{array}{llll}2.7504317 & -9.140017506 & -5.204113586\end{array}$

$\begin{array}{llll}3.054476240 & -9.090560728 & -5.205556890\end{array}$

$\begin{array}{llll}3.054476240 & -9.090560128 & -5.205556890 \\ 3.200928512 & -9.039401677 & -5.206350159 \\ 3.348355520 & -8.985655214 & -5.206510374\end{array}$

TI Thrust unit Vector (EII M.D 000 ) $\begin{array}{lllll}1.826309911 & -9.434451754 & -5.170650526\end{array}$ 


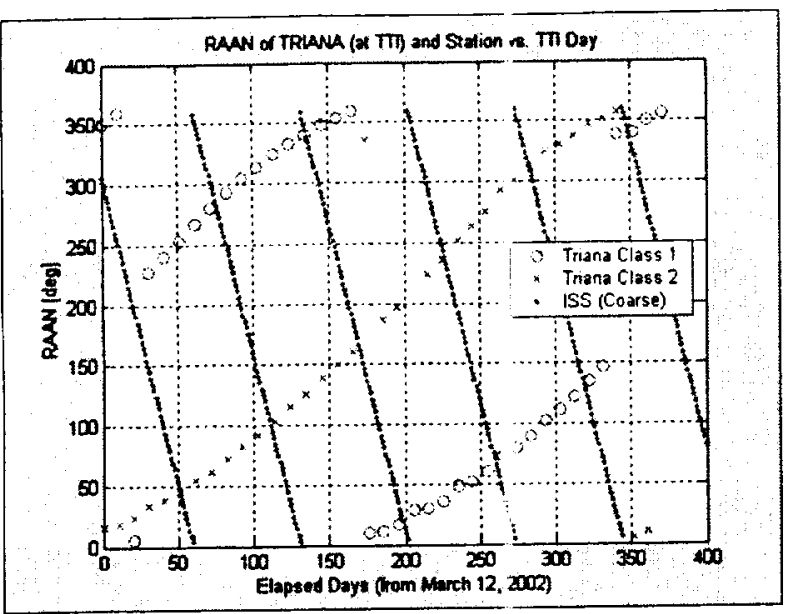

Figure 10: RAAN plot showing 12 opportunit es on joint mission [3]

\section{Optional Shuttle Scenarios}

Several alternate Shuttle mission scenarios have been considered in an attempt to make Triana as compatible as possible with the Shuttle manifest. 'Triana was originally meant to fly on STS-107, at 150 nautical miles with an inclination of $39^{\circ}$, but that opportunity evaporated due to circumstances outside the control of Goddard, or anyone involved in the Triana project. Trianı has re-baselined for a generic research flight at 150 nat tical miles with an inclination of $28.5^{\circ}$. This is considered to be the most likely (Shuttle) scenario. The inclination change causes no real problems. Generator is able to tind solutions over a very wide range of inclinations, as elidenced below, without changing the shape of the final Lissajous.

The feasibility of taking Triana along on a retrieval (e.g. UARS) or a rendezvous (e.g. Space Station) mission has been explored. These scenarios pise a problem only in that the right ascension of the ascending node (RAAN) of an object in low earth orbit regresses at a rate of several degrees per day (5 for Space Station, for example), due to the Earth's oblateness, and the RA if Triana's TTI point precesses at roughly $1 \%$ day, due to the Earth's motion about the sun. This creates a situation in which the two coincide (a requirement, if the Shuttl is going to do both on the same flight) only 6 times per year. This number can be doubled by recognizing the fat that their exists one set of TTI points for use near a LEO ascending node and one set for use near a LEO descending node. Combining these sets gives 12 opportunities per vear (Figure 10).

A "random release" joint Space Station mission has also been considered. "Random release" refers to the right ascension (RA) constraint on Triani's release point. In this scenario, the Shuttle is free to release Triana on any orbit, of any mission, as long as the Triana Project is allowed to still specify where in the orbit the observatory is released. This way, the Triana Project can constrain Triana's RA at release to lie within a given hemisphere, and, consequently, its apogee (post (UUS burn) to lie within a given hemisphere. The GUS ballast, in this case, is set such that Triana is injected into a highly elliptical orbit (HEO) with a period of $14 \mathrm{da}$ s, twice the moon's orbital period, so as to minimize the moon's impact on

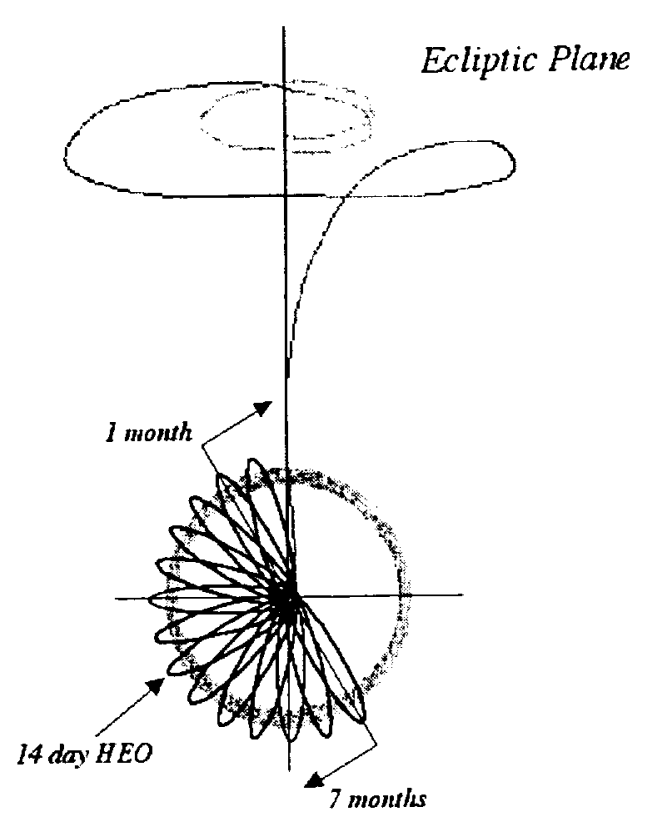

Triana loiters in HEO for up to 7 months

Figure 11: Illustration of "random release" Shuttle mission scenario

the orbit. This way, Triana can loiter while the Earth-sun line precesses around (at roughly $1^{\circ}$ per day) to line up with Triana's apogee (Figure 11). Triana's hydrazine system is then used to send Triana the rest of the way to L1. Since the release and GUS $\Delta V$ corrections, as well as the final TTI maneuver, can all be done at perigees, this scenario does not differ, considerably, from the baseline scenario, in terms of total $\Delta V$ costs.

\section{Looking for an ELV}

In light of the lack of success in finding a spot on any near-term Shuttle flight, the Triana Project has explored various expendable launch vehicle (ELV) options, as well, in hopes that an opportunity might ultimately present itself. To that end, Triana's energy requirement can be summarized in one of two ways. Either the observatory, itself, needs to be boosted to a $C_{3}$ of $-0.7 \mathrm{~km}^{2} / \mathrm{s}^{2}$, or the Triana/GUS stack needs to be placed in a sufficiently high-energy LEO such that the $\Delta V$ provided by the GUS is enough to put Triana on the proper trajectory. These relationships are shown in Figures 12 and 13, with the difference being the weight and the required velocities.

Domestically, Delta II ELVs have the capability to boost Triana directly onto its transfer trajectory [4]. The Triana Project considered them at length. Even a flight out of Vandenberg Air Force Base, on the U.S. West Coast, where the resulting inclination would have been in excess of $60^{\circ}$, was considered. Generator was able to find solutions at inclinations as high as $80^{\circ}$. A Delta II appears to be a very viable option, but has never come to fruition, primarily due to a lack of such funding on the Triana Project. Triana's Shuttle launch was meant to be "free". 


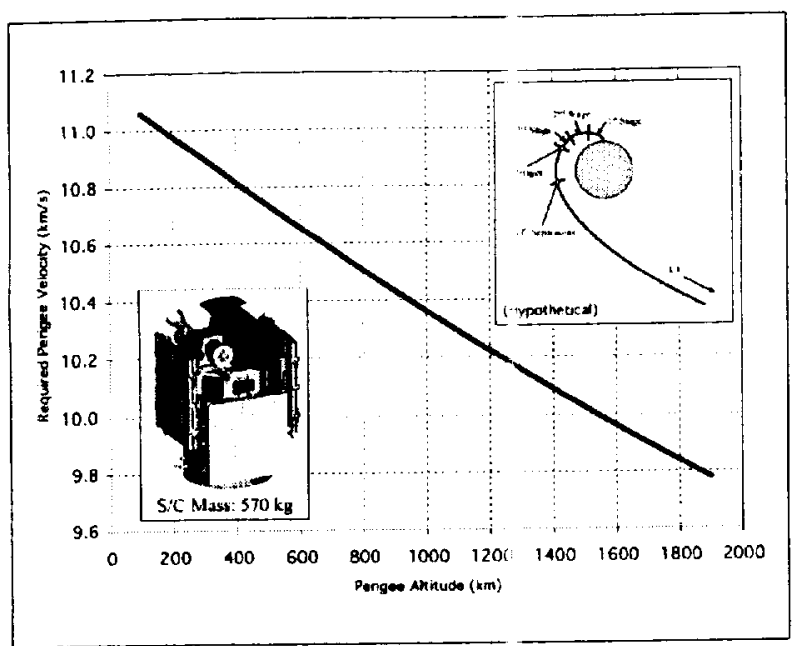

Figure 12: Energy requirement for Triana o' iservatory $\left(C_{3}\right.$ of -0.7$)$

Discussions with United Start, a Lelaware based corporation owned by the American company Assured Space Access, Inc. and the Russian company ZAO Puskovie Uslugi (Launch Service Provider) [5] have led to the conclusion that a 3-stage version of the Ukrainian Tsyklon vehicle, being proposed by United St art, would be capable of putting the Triana/GUS stack into an orbit with a perigee of $120 \mathrm{~km}$ and an apogee of $200 \mathrm{~km}$ at an inclination of $51.6^{\circ}$. Figure 14 shows that, as long as the orbit's perigee is within roughly $60^{\circ}$ of Triana's TTI point, the Tsyklon/GUS combination is enough to get Triana to L1. It is assumed that the Tsyklon vehicle places Triana/GUS in an orbit whose RAAN is specified by the Triana Project.

\section{Triangular Transfer Trajectories}

The final and possibly the most difficult to accommodate ELV considered for use by the Triana Project is the French Ariane 5. What makes this opportunity difficult is the fact that Triana would need to te co-manifested with some other payload, and the Ariane's standard product is a rather specific geostationary transfer orbit (GTO). The Ariane "constraints" would put Trian $₫$ into an orbit who's line of apsides is as much as 45 minutes ( $11.25^{\circ}$ in RA) off the Earth-sun line and $23.4^{\circ}$ off the ecliptic [6]. Compared to the Shuttle tolerance of $3.8^{\circ}$ in RA, $11.25^{\circ}$ is excessive. What makes this sccnario possible is a "triangular" transfer trajectory first proposed by Purdue University as a possible Shuttle contingency option [7]. These trajectories have departing asy inptotes that are much farther off the Earth-sun line than tixe baseline trajectory (which is right along the Earth-sun line), easily encompassing the $11.25^{\circ}$ (Figure 15).

Putting Triana into an orbit $w$ th a 7.5 day period (roughly) would allow the triangular transfer trajectories to be achieved, ultimately, from anywhere within the line of apsides RA range (Figure 16). It would just be a matter of letting the Earth-sun line precess to the proper spot, while waiting in up to 2 phasing loops.

As for the inclination issue, it's possible to enter into a Lissajous at L1 from any of the riven ecliptic inclinations, but doing so determines the $z$-amplitude of the

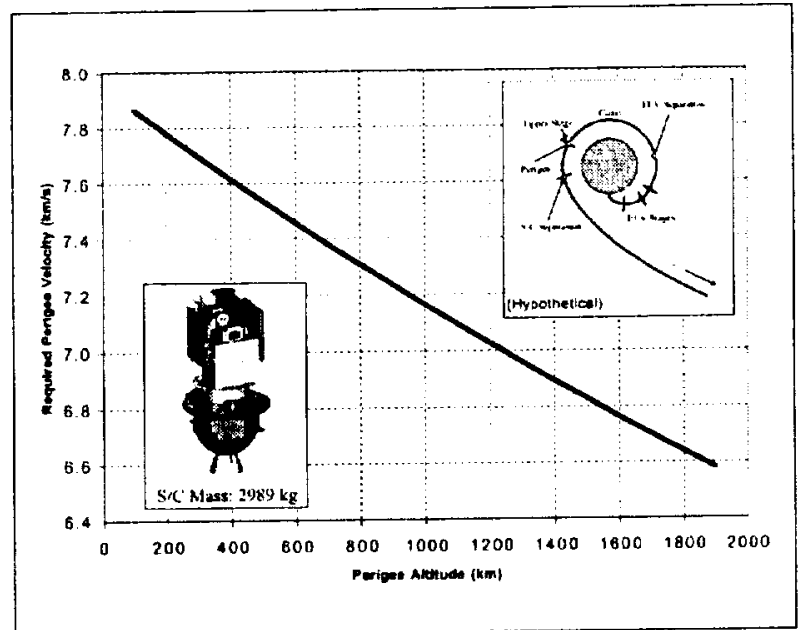

Figure 13: Requirement placed on LEO state for use by Triana/GUS

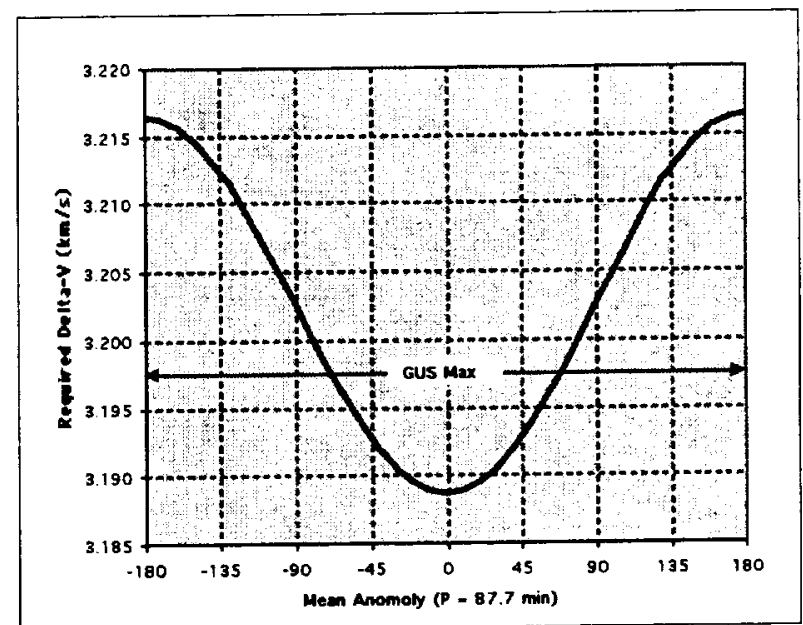

Figure 14: Tsyklon/GUS "energy balance" for getting Triana to L1

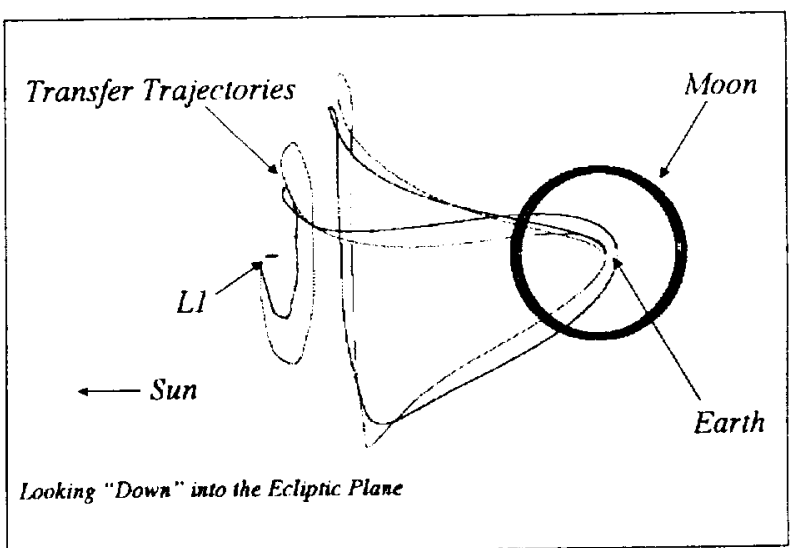

Figure 15: "Triangular" transfer trajectories for use in getting to $\mathrm{L} 1$

resulting Lissajous (Figure 17). A $\Delta V$ would be required to lower (or raise) the $\mathrm{z}$-amplitude to match the mission orbit. The cost of doing so was shown to be manageable (10's of $\mathrm{m} / \mathrm{s}$ ). There is an additional issue with particularly low inclinations in that there will be a communications loss as the observatory passes in front of the sun. All of these nuances are ultimately manageable [8]. 


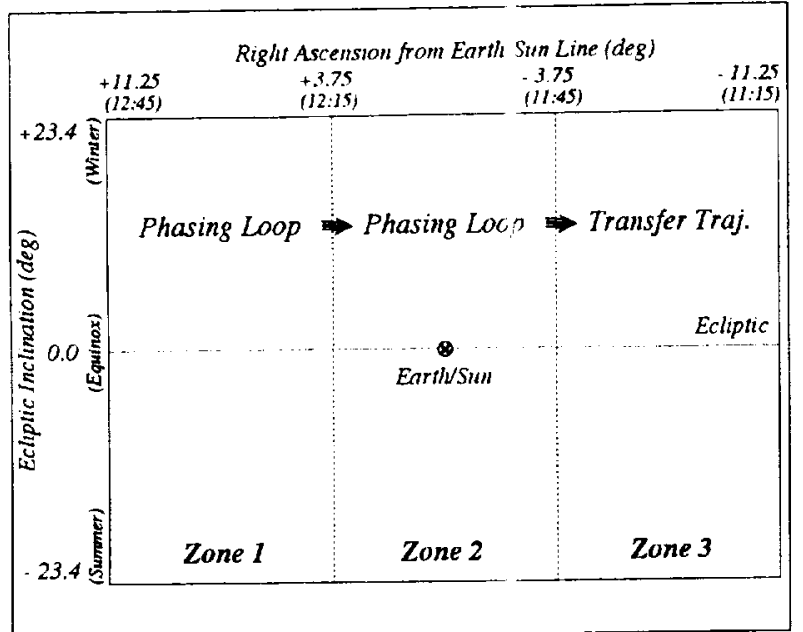

Figure 16: Line of apsides with respect to the Earth-sun line (Ariane)

\section{Conclusion}

There are several ways of getting a satellite, such as Triana, to L1, and they're not all equal. Clearly the most sensible solution is to have a dedicaled launch vehicle for any satellite that is going to $\mathrm{Ll}$, or any Lagrange point for that matter. From the standpoint of targeting, Lagrange point missions are essentially no different than interplanetary missions. They're relatively hard to hit. Anything that makes that task more difficult than it already is should be avoided.

The sensible approach not withstanding, Goddard Space Flight Center has shown that there are several options for getting Triana to L1, apart from the baseline Shuttle deployment scenario. It was shown that there are feasible ways of flying Triana on a rendezvous/retrieval type Shuttle mission and that the TTI point RA constraint can, if necessary, be lifted, through the use of phasing loops, allowing for even greater flexibility. The inclination of the LEO orbit from which Triana departs was also shown to be relatively unimportant. This was evident in the Delta II study, which looked at in linations as high as $80^{\circ}$. Other considered options include a version of the Ukrainian Tsyklon vehicle and a co-manifested flight on an Ariane 5 launch vehicle. The lalter option would involve the use of phasing loops and a "triangular" transfer trajectory. Such flexibilities in nission planning approaches make a plethora of options ultimately available.

\section{References}

[1] J. Watzin; "The Triana Mission Implementation - A Unique Mission with a Unique A pproach"; 2001.

[2] C. Tooley, M. Houghton, et al.; "The IRIS-GUS Shuttle Borne Upper Stage Systein" AIAA 2002-3761.

[3] G. Marr, S. Cooley, et al.; "Trima Trajectory Design Peer Review" (Package); September 26, 2001.

[4] Delta II Payload Planners Guide - www.boeing.com

[5] United Start Corporation - www.tunitedstart.com
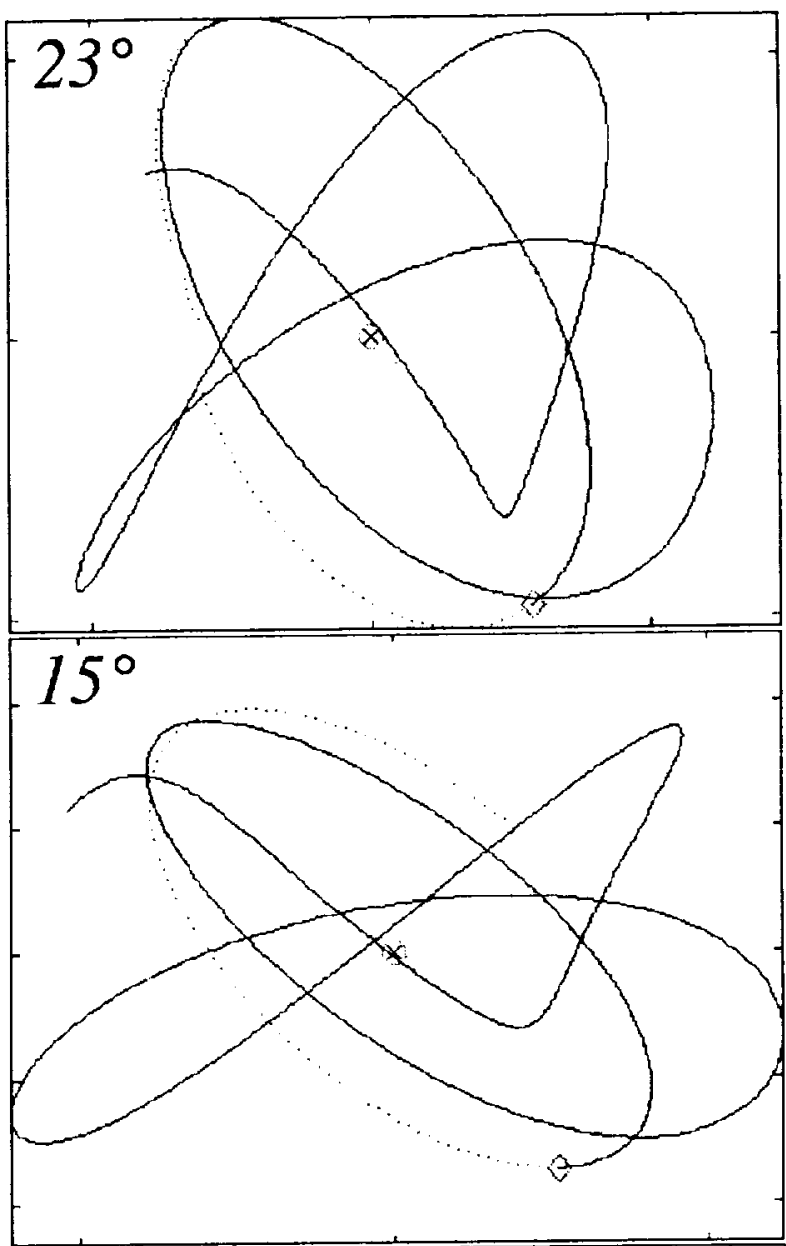

$1^{\circ}$ inclination (ecliptic) in LEO

\section{From Earth}

Figure 17: "Triangular" transfer trajectories for different inclinations

[6] Ariane 5 User's Manual - www.arianespace.com

[7] K. Howell, J. Anderson; "Triana Contingency Analysis Progress Report"; March 2001, IOM AAE-0140-001.

[8] M. Beckman; Personal communications and analysis. 